1 Jacques $\mathrm{H}$. Psychiatry experience in foundation years is linked to higher rate of application to specialty training in the discipline. BMJ Careers 2013; 16 Jan (http://careers.bmj.com/careers/advice/viewarticle.html?id=20010463)

2 Archdall C, Atapattu T, Anderson E. Qualitative study of medical students' experiences of a psychiatric attachment. Psychiatrist 2013; 37 $21-4$.

Aashish Tagore, specialist registrar in adult psychiatry, Mersey Care NHS Trust, UK, email: aashishtagore@hotmail.com

doi: $10.1192 / p b .37 .4 .145 a$

\section{Why choose psychiatry? Report on a qualitative workshop}

As trainees, we thought that examining the views of trainees who have already chosen psychiatry might add to our understanding of the factors involved in career choice.

In November 2009, the London Deanery School of Psychiatry hosted its annual trainee conference themed 'Recruitment - Everybody's Business'. There we facilitated two identical, optional qualitative workshops entitled 'Choosing psychiatry as a career - influencing the next generation'. Each workshop was attended by 30 individuals, and facilitated by 5 senior trainees and 4 medical students who took verbatim notes. Framing questions were used to identify key themes regarding positive and negative influences on career choice.

Of the 184 delegates, 86 (47\%) were male and 106 (58\%) reported Black and minority ethnic backgrounds. Two of us (M.P. and K.F.) used thematic coding until saturation of themes emerged. We report these themes briefly here.

Participants described the doctor-patient relationship, the human narrative ('psychiatry is about stories, rather than abstract algorithms'), and the rapidly evolving nature of psychiatry ('you can do things which are ground-breaking') as attractors to the field. They emphasised the importance of conveying the high work satisfaction and good work-life balance, job flexibility, and 'colourful colleagues [who make it] fun' to medical students.

Factors that nearly discouraged trainees from a career in psychiatry included stigma and negative attitudes towards the profession from colleagues. Several trainees described unhelpful experiences during their foundation years: being 'ignored by a consultant surgeon after disclosing an interest in psychiatry', and how physician colleagues 'did not have a positive thing to say about the specialty'. Medical student participants as a subgroup also commented on the effect of negative attitudes from other professionals ('boring job', being seen as 'less of a doctor' and 'becoming mad as a psychiatrist'). Such inter-professional stigma towards psychiatry has been reported to negatively influence choice of psychiatry as a career. ${ }^{1,2}$ Intra-professional stigma and 'negative attitudes and behaviour' were observed among teachers, who were reportedly 'a bit embarrassed about being psychiatrists'. A further theme was the lack of professional confidence and evident role uncertainty among psychiatrists: 'Psychiatrists have big issues with the specialty they've chosen - we don't feel confident we're as valuable as other medical specialties; we're not sure what our role is and what we contribute'.

When trainee psychiatrists were asked what they could do individually and collectively to inspire the next generation, the main emphasis was on high-quality teaching and clinical placements, making time for experiential teaching, and helping students to feel part of the team. The importance of positive modelling by psychiatrists ${ }^{3,4}$ was also noted, for example, being 'passionate about psychiatry'.

Changes in attitude and perception, both within and without psychiatry, along with improved student placements, role modelling and teaching quality must occur if we are to address low recruitment and, in the words of one of the participants, 'make the specialty something to aspire to, rather than something into which people drift'.

1 Buchanan A, Bhugra D. Attitude of the medical profession to psychiatry. Acta Psychiatr Scand 1992; 85: 1-5.

2 Holmes D, Tumiel-Berhalter LM, Zayas LE, Watkins R. Bashing of medical specialties: students' experiences and recommendations. Fam Med 2008; 40: 400-6.

3 McParland M, Noble LM, Livingstone $G$. The effect of a psychiatric attachment on students' attitudes to and intention to pursue psychiatry as a career. Med Educ 2003; 37: 447-54.

4 Plaice E, Heard S, Moss F. How important are role models in making good doctors? BMJ 2002; 325: 707-10.

Dr Michael Paddock, Paediatric Specialty Trainee, Northwick Park Hospital, North West London Hospitals NHS Trust, UK, email: michael.paddock@ doctors.org.uk; Dr Kitty Farooq, Consultant Psychiatrist, Oxleas NHS Foundation Trust, UK; Dr S. Neil Sarkar, Locum Consultant Psychiatrist, Primary Care Liaison Psychiatry, Central and North West London NHS Foundation Trust, UK; Dr Tulha Aga, Consultant Psychiatrist, Medway Recovery Team, Kent and Medway NHS and Social Care Partnership Trust, Gillingham, UK; Dr Greg Lydall, Consultant Psychiatrist, Castel Hospital, Guernsey, Channel Islands.

doi: $10.1192 / p b .37 .4 .146$

\section{What about old age psychiatry?}

We welcome the article by Oakley et $a l_{;}^{1}$ creating a robust training programme more focused on developing medical expertise will go a long way to addressing the identity crisis currently ravaging psychiatry. However, we were concerned about the proposed structure of postgraduate training with regard to the dearth of old age psychiatry experience. Currently, it is possible to undertake one, and in some cases two, 6-month old age placements at any point during core training. The proposed training reduces this significantly to one 4-month placement as a CT1. All other subspecialties are represented by 6-month placements between CT2 and CT4. It is unclear why old age psychiatry has been excluded from this. Although old age experience at an early stage in training is important, this can only serve as a basic introduction to the specialty and will not allow for the development of expertise and excellence as emphasised in the Tooke report. ${ }^{2}$

It seems perverse that the authors recommend increasing the total duration of training while reducing the time spent in old age psychiatry. To exclude old age psychiatry from CT2-4 placements suggests non-parity with other psychiatric specialties. We fear this may harm recruitment to the field, as it becomes a distant memory by the time choices for specialisation are made as a CT4. It neglects to tackle the situation of trainees who are undecided about old age psychiatry and would benefit from further experience to aid their decision, or those who have, early on, settled on a career 